\title{
META ANALYSIS: THE SMOKING EFFECT ON GASTRO- ESOPHAGEAL REFLUX DISEASE IN ADOLESCENTS
}

\author{
Septyandi Ramadhan, Bhisma Murti \\ Masters Program in Public Health, Universitas Sebelas Maret
}

\begin{abstract}
Background: Recent studies have shown the effects of lifestyle modifications on gastroesophageal reflux disease and reflux symptoms, including smoking. Smoking acutely increase the rate at which acid reflux events occurred. It is occurred by transient lower oesophageal sphincter relaxations. The purpose of this study was to investigate the effect of smoking on gastroesophageal reflux disease in adolesccents.

Subjects and Method: This was a meta-analysis of smoking with gastroesophageal reflux disease. This study was conducted by PRISMA flow diagram. The articles were collected from Google Scholar, Pubmed, and Science Direct databases, published from 2020 to 2021. Keywords used "smoking" OR "cigarette smoke" OR AND "GERD" OR AND "Adolescent" OR "Teenage" AND "logistic regression". Eligibility criteria were defined using the PICO model as follows, (1) population: adolescents, (2) intervention: smoking, (3) comparison: non smoking, and (4) outcome: gastroesophageal reflux disease. Articles that met the criteria were analyzed by Revman 5.3.

Results: A meta-analysis combined six studies articles from China, United States, Saudi Arabia, Australia, and Netherlands showed that smoking increased the risk of gastroesophageal reflux disease in adolescents $(\mathrm{aOR}=1.81 ; 95 \% \mathrm{CI}=1.55$ to 2.13 ; $\mathrm{p}<0.001)$.

Conclusion: Smoking increases the risk of gastroesophageal reflux disease in adolescents.
\end{abstract}

Keywords: acid reflux, gastroesophageal reflux disease, smoking

\section{Correspondence:}

Septyandi Ramadhan. Masters Program in Public Health, Universitas Sebelas Maret. Jl. Ir. Sutami 36A, Surakarta 57126, Central Java. Email: septyandiramadhan@student.uns.ac.id. Mobile: 081936553398.

The $8^{\text {th }}$ International Conference on Public Health

Solo, Indonesia, November 17-18, 2021 | 51

https://doi.org/10.26911/AB.Epidemiology.ICPH.08.2021.31 